\title{
Thermal management of photovoltaic panel with nano-enhanced phase change material at different inclinations
}

\section{UNNIKRISHNAN KARTHAMADATHIL SASIDHARAN}

NITC: National Institute of Technology Calicut https://orcid.org/0000-0002-2231-5391

ROHINIKUMAR BANDARU ( $\nabla$ rohinikumar@nitc.ac.in )

NITC: National Institute of Technology Calicut https://orcid.org/0000-0002-3975-3996

\section{Research Article}

Keywords: thermal, nepcm, nanoparticles, fraction, energy, natural, convection

Posted Date: August 17th, 2021

DOl: https://doi.org/10.21203/rs.3.rs-772813/v1

License: (c) (1) This work is licensed under a Creative Commons Attribution 4.0 International License.

Read Full License 


\title{
Thermal management of photovoltaic panel with nano-enhanced phase change material at different inclinations Unnikrishnan Karthamadathil Sasidharan', Rohinikumar Bandaru,** \\ ${ }^{1}$ CFD Laboratory, Mechanical Engineering Department, National Institute of Technology Calicut, Kozhikode-673601, Kerala, India \\ *Corresponding author email: rohinikumar@nitc.ac.in, : +91-9744480751
}

\begin{abstract}
Photovoltaic (PV) panel, coupled with phase change material (PCM), has attracted broad attention for the panel's thermal management. Despite the higher energy storage capability of PCMs, the main disadvantage is their low thermal conductivity which is compensated to an extent with the nano-enhanced PCMs (NEPCMs). In this study, numerical simulations are carried out to compare the natural convection phenomena and thermal response of PVNEPCM with simple PV-PCM for various tilt angles. $\mathrm{CuO}$ nanoparticles with a $4 \%$ volume concentration are selected for NEPCM. The thermal performance of PV-NEPCM at inclinations of $0^{\circ}, 15^{\circ}, 30^{\circ}$, and $45^{\circ}$ are compared with a simple PV-PCM system. The average temperature of PV, liquid fraction and thermal energy stored in PCM, the PV efficiency are compared for PV-PCM and PV-NEPCM systems. Results show that the loading of nanoparticles increases the conduction heat transfer inside PCM. It has also been shown that at lower inclinations, the use of NEPCM is more effective due to the dominance of conduction heat transfer. At higher tilt angles, natural convection plays a significant role in the heat transfer mechanism inside PCM. By using NEPCM, the maximum decrease in $\mathrm{PV}$ temperature of $1.11^{\circ} \mathrm{C}$ and maximum improvement in the liquid fraction $(7.6 \%)$ are achieved when $\theta=0^{\circ}$ compared to simple PCM. Enhancement of thermal energy stored in PCM increases slightly upon adding nanoparticles, and the highest improvement is obtained for $\theta=0^{\circ}$. Maximum enhancement of PV efficiency is found to be $1.6 \%$ for $\theta=0^{\circ}$ inclination on adding nanoparticles at a fraction of 4 vol. $\%$. Keywords: PV, nano-enhanced PCM, nanoparticles, natural convection, liquid fraction.
\end{abstract}

\section{Introduction}

Energy utilisation is growing exponentially in this era of rising population, and the demand for renewable energy is increasing significantly from the last decade onwards. Solar energy, which is derived from the sun, is the most abundant renewable energy that can easily meet today's demands. With the help of solar photovoltaics, solar energy from the sun that falls on the earth's surface can be transformed into electrical energy. Photovoltaics (PV), also referred to as solar cells, are solid-state devices that directly converts solar energy into electricity. Depending on the PV cell material and climatic conditions, a standard PV converts 6-20\% of the incident solar radiation into electricity, and the remainder is converted to thermal energy, which increases the temperature of the PV cell to $50^{\circ} \mathrm{C}$ above ambient (David Tan 2011). The temperature coefficient of power is an important differentiator in solar PV efficiency, particularly in hot climates. The efficiency of PV cells degrades as the temperature of the cells increase (Hegedus 2003).

Wysocki and Rappaport (1960) theoretically investigated solar PV conversion over a temperature range of $0-400^{\circ} \mathrm{C}$ by varying band gaps and found that maximum conversion efficiency occurs with materials having high bandgap. Radziemska and Klugmann (2002) experimentally showed that the product of $V_{o c} I_{s c}$ of PV cell degrades about $0.8 \%$ for every $1 \mathrm{~K}$ increase in temperature. A crystalline solar cell's power output decreases by $0.4 \%$ for every 1 K rise in temperature (E. Radziemska 2002). Skoplaki and Palyvos (2009) presented correlations for PV's power and efficiency as a function of its operating temperature. The PV module's degradation rate is doubled for 
every $10^{\circ} \mathrm{C}$ rises in its temperature (Otth and Ross 1983 ). So, temperature management of PV panels is very much essential for its best performance.

Passive temperature regulation of PV using phase change material (PCM) has received much attention in this regard. PV modules can be efficiently cooled using phase PCMs. A typical solid-liquid PCM with an appropriate melting point and heat of fusion is mounted to the backside of the PV panel to establish a PV-PCM system that ensures lower PV panel temperature and hence higher electrical efficiency. When PCM is attached at the bottom surface of PV, it absorbs the excessive thermal energy generated by the PV panel in the form of latent heat, which can be utilised for other purposes. This helps to maintain the panel temperature lower for a considerable time and increases the overall efficiency of the system.

Hasan et al. (2010) evaluated the performance of PV integrated with five different PCMs with three insolations and showed that mass and thermal conductivity of PCM along with thermal conductivity of PCM container play a significant role in the PV-PCM system's performance. Park et al. (2014) carried out an experimental and numerical analysis to examine the performance of a vertical PV-PCM system and compared it with a standard PV module under actual outdoor climate conditions. The results showed an increase of 1-1.5\% in PV electric power generation. The numerical analysis and experimental investigation by Mahamudul et al. (2016) showed that with RT35 as a PCM layer of $0.02 \mathrm{~m}$ thickness, the module's surface temperature is reduced by $10^{\circ} \mathrm{C}$ for $4-6$ hours. The effects of inclination angle, concentration ratio, and PCM thickness on the performance of a CPV-PCM system were studied numerically by Emam et al. (2017) using $\mathrm{CaCl}_{2}-6 \mathrm{H}_{2} \mathrm{O}$ as PCM. Khanna et al. (2017) analysed the effects of the PV-PCM system's tilt-angle, wind-direction, wind-velocity, ambient temperature and phase transition temperature on the rate of PCM heat extraction and PV-PCM system temperature. The PV panel temperature in the PV-PCM system dropped from $43.4^{\circ} \mathrm{C}$ to $34.5^{\circ} \mathrm{C}$. Gkouskos and Tsoutsos (2012) presented an experimental study of a PV-PCM system to decrease the temperature of the PV panel and to increase the overall efficiency of the PV-PCM system. PV temperature, when coupled with RT27 as PCM, found to be close to $25^{\circ} \mathrm{C}$. A three-dimensional numerical model was simulated and the results were compared and validated with the results of the two-dimensional model and experimental studies by Huang et al. (2006). Brano et al. (2013) developed a one-dimensional numerical model based on an explicit finite difference method for formulating energy balance for the PV-PCM system to increase its performance. The results of the numerical simulation were in good agreement with the data obtained from the real-time monitoring device. Ceylan et al. (2017) examined the effectiveness of paraffin wax on reducing the temperature of CPV panels and it was reported that the panel temperature was reduced by $15^{\circ} \mathrm{C}$ on an average compared to the system without paraffin.

Nouira and Sammouda (2018) conducted a numerical study to know the impact of integrating different PCMs with different thicknesses on the system's performance. Kant et al. (2016) numerically studied the natural convection effect within melting PCM (RT35HC) and its influence on PV performance using COMSOL Multiphysics software. The effect of wind velocity, angle of inclination of the PV panel coupled with PCM was studied and compared with a simple PV case, and it was observed that a drop in PV temperature by $3^{\circ} \mathrm{C}$ in the presence of convection in PCM. Sinks et al. (2020) considered a PV-PCM heat sink and finned PCM (FPCM) heat sink for PV panel cooling and observed that the PCM incorporated with heat sinks could reduce the maximum temperature by $13^{\circ} \mathrm{C}$ whereas FPCM can enhance cooling by $19^{\circ} \mathrm{C}$.

Since PCMs generally have low thermal conductivity, different strategies are employed to improve it using composite PCMs, incorporating metal foams and using multiple PCMs. Klemm et al. (2017) numerically showed 
that temperature could be reduced by approximately $2^{\circ} \mathrm{C}$ compared to bare PV using a composite PV-PCM (PCMfilled metallic fibre structure) system. Maiti et al. (2011) incorporated a thick bed of metal-embedded paraffin wax as PCM and maintained the PV temperature at $60^{\circ} \mathrm{C}-65^{\circ} \mathrm{C}$ for three hours. This led to a power output overall gain of 55\%. The system was found to be beneficial even with low-velocity conditions. By integrating micro-fins, PCM and nano-enhanced PCM, Sourav et al. (2019) numerically and experimentally studied the effect of passive cooling technique (n-PCM) to lower PV temperature. Luo et al. (2017) developed a PV-PCM device using shapestable composite paraffin PCM and found that form-stable composite PCM helps to control PV panels' temperature easily. Atkin and Farid (2015) have experimentally modelled and tested the use of PCM infused graphite with an external finned thermal sink for the temperature control of PV panels. The PV panel without any cooling technique, the PV panel PCM infused graphite attached to the rear, and the PV with a combination of PCM infused graphite and the finned heat sink attached to the bottom were studied in four situations. The latter was found to be beneficial since the reduction in temperature and increase in efficiency is more in this. The effect of using white petroleum jelly (pure form) and composite PCM consisting of white petroleum jelly, copper and graphite on the thermal and electrical behaviour of a PV panel was explored by Hachem et al. (2017). The overall performance of a concentrated PV (CPV) nanoparticle-PCM was studied by Zarma et al. (2019) with different nanoparticles $\left(\mathrm{Al}_{2} \mathrm{O}_{3}, \mathrm{CuO}\right.$ and $\left.\mathrm{SiO}_{2}\right)$. Nanoparticles were found to be enhancing the thermal conductivity of PCM and thereby reducing the temperature of $\mathrm{CPV}$.

In general, the critical takeaway is that PCM is immensely helpful in regulating PV panel temperature by absorbing excessive thermal energy of PV, which is not converted into electrical energy and stored as latent heat of PCM. The major drawback of paraffin PCM is its low thermal conductivity. So, different methods such as the inclusion of fins, the loading of nanoparticles are needed to be adopted to increase the thermal conductivity of PCM, which may improve the conduction heat transfer rate within the PCM. Considering the inherent advantages of using finned PCM and composite nano - PCM in thermal regulation of PV, as evident from the literature survey, there is a need to explore the effectiveness of loading nanoparticles in PCM integrated with fins in the performance of the PV-PCM system with respect to different inclinations. Secondly, analysis needs to be conducted to study the performance of finned PV-NEPCM systems having varying fin numbers. In this paper, numerical modelling and simulation are carried out to analyse the overall thermal behaviour and its consequent effect on the performance of the PV-NEPCM system. CuO nanoparticles with volume concentration $(\varphi) 4 \%$ dispersed in RT25HC PCM is taken as NEPCM. The main objectives of the present work are to determine the heat transfer characteristics such as the transient temperature of the PV panel, liquid fraction and thermal energy storage and to evaluate the effect on the performance of the PV module of PV-NEPCM system with different inclinations by comparing with that of the PV-PCM system.

\section{Physical system description and mathematical formulation}

Fig. 1 shows the schematic diagram of the geometry of the PV-NEPCM system. The PV module consists of five different layers. PCM with nanoparticles is attached to the bottom of the PV module with the help of aluminium plates, as shown in Fig. 1, to establish the PV-NEPCM system. When the volumetric concentration of the nanoparticles is zero, the PV-NEPCM system will become a typical PV-PCM system. The tilt angle of the PVNEPCM system $(\theta)$ is varied to get different operational configurations for analysing the performance of the system. The following assumptions are considered for the mathematical modelling of the PV-NEPCM system 


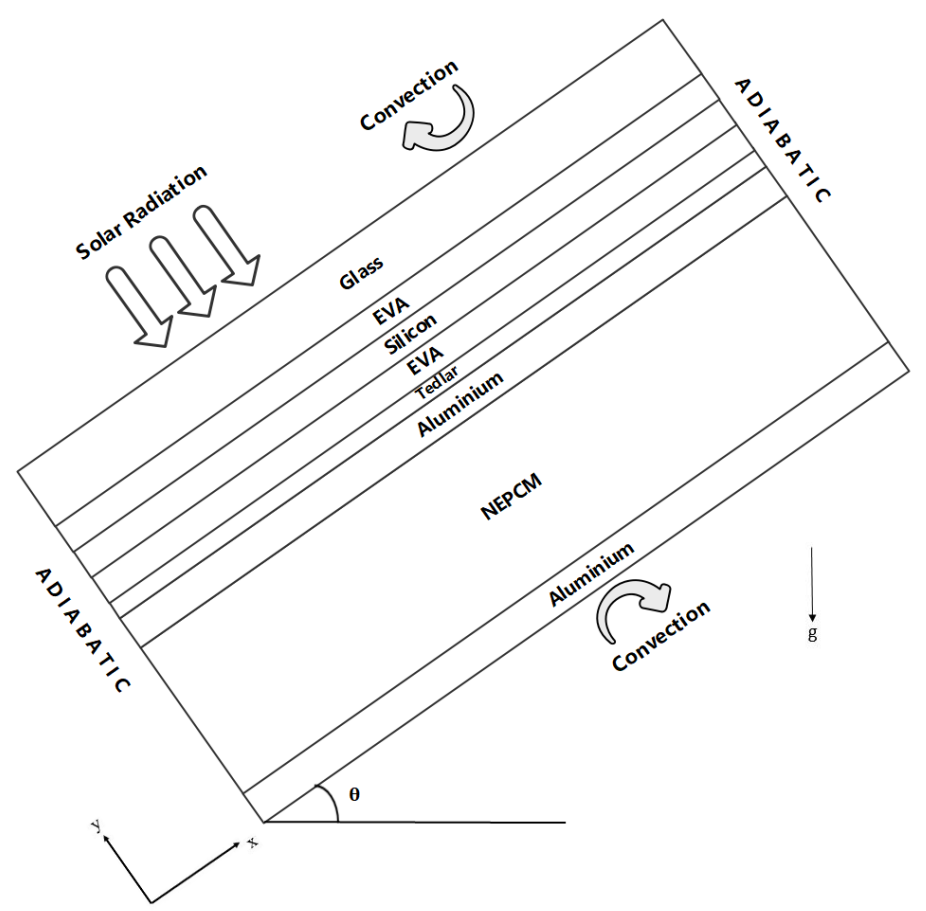

Fig. 1 Geometry of PV-NEPCM system

1. The incident radiation on the PV is uniform for all the configurations of the system.

2. The temperature and velocity fields of the PV-NEPCM system is two dimensional in the $x-y$ plane.

3. PCM in the fluid state is assumed as Newtonian.

4. The flow of melted PCM is unsteady, two dimensional, laminar and incompressible.

5. Materials of different layers of PV module are treated as isotropic and homogeneous.

6. Dust and rain effects are not considered.

7. Resistive losses in the PV cell are not considered.

8. The effect of radiation heat transfer is neglected.

The portion of incident solar radiation $\left(G_{T}\right)$ that transmits through the glass cover and is absorbed by the PV cell is $G_{T}(\tau \alpha)_{e f f}$, where $(\tau \alpha)_{e f f}$ is the effective product of the glass cover's transmissivity and the PV cell's absorptivity. The other major portion of this is converted into thermal energy and available for heat transfer $\left(\dot{Q}_{g}\right)$, which can be written as

$$
\dot{Q}_{g}=\left[(\tau \alpha)_{e f f} G_{T}-\eta_{P V} G_{T}\right] / t_{s i}
$$

where $\dot{Q}_{g}$ is the heat source in $W / m^{3}, \eta_{P V}$ is the electric efficiency of PV cell and can be defined as (Evans and

Florschuetz 1977)

$$
\eta_{P V}=20\left[1-\beta_{c}\left(T_{P V}-25^{\circ} \mathrm{C}\right)\right]
$$

\subsection{Solid domain}



the diffusion heat transfer equation applied to the solid parts of the system. Governing equation for temperature distribution of different layers of PV module is

$$
\rho C_{p} \frac{\partial T}{\partial t}=k\left(\frac{\partial^{2} T}{\partial x^{2}}+\frac{\partial^{2} T}{\partial y^{2}}\right)+\dot{Q}_{g}
$$

where $\dot{Q}_{g}$ is the heat source term and this term is applicable to the silicon layer of PV only.

143

144

145

146

147

148

149

150

151

152

\subsection{Modelling of NEPCM}

Energy - porosity technique (Brent et al. 1988) (C. 1978) along with Boussinesq approximation (Mat et al. 2013) is used to model the PCM, which predicts both the melt front's location and morphology at different instants with modest computational requirements. The temperature and the instantaneous velocities of the melted PCM can be simulated using thermal energy equation, Navier- Stokes equations and continuity equation for a Newtonian and incompressible fluid, as shown in the equations:

Energy:

$$
\rho c_{p} \frac{\partial T}{\partial t}=\frac{\partial}{\partial x}\left(k \frac{\partial T}{\partial x}-\rho c_{p} u T\right)+\frac{\partial}{\partial y}\left(k \frac{\partial T}{\partial y}-\rho c_{p} v T\right)
$$

$x$-momentum:

$$
\rho\left(\frac{\partial u}{\partial t}+u \frac{\partial u}{\partial x}+v \frac{\partial u}{\partial y}\right)=-\frac{\partial P}{\partial x}+\mu\left(\frac{\partial^{2} u}{\partial x^{2}}+\frac{\partial^{2} u}{\partial y^{2}}\right)+\rho g_{x} \beta\left(T-T_{m}\right)+F_{x}
$$

y-momentum: $\quad \rho\left(\frac{\partial v}{\partial t}+u \frac{\partial v}{\partial x}+v \frac{\partial v}{\partial y}\right)=-\frac{\partial P}{\partial y}+\mu\left(\frac{\partial^{2} v}{\partial x^{2}}+\frac{\partial^{2} v}{\partial y^{2}}\right)+\rho g_{y} \beta\left(T-T_{m}\right)+F_{y}$

Continuity: $\quad \frac{\partial u}{\partial x}+\frac{\partial v}{\partial y}=0$

Where $\rho, c_{p}, k, \mu$ and $\beta$ are the density, heat capacity, thermal conductivity, dynamic viscosity and thermal expansion coefficient of the PCM, respectively. $u$ and $v$ are velocities of melted PCM in the $x$ and $y$-directions, respectively. The function $B(T)$ is used to model liquid fraction and thermo-physical changes in PCM (Biwole et al. 2013)

$$
B(T)=\left\{\begin{array}{cc}
0 & \text { if } T<\left(T_{m}-\Delta T / 2\right) \\
\left(T-T_{m}+\Delta T / 2\right) /(\Delta T) & \text { if }\left(T_{m}-\Delta T / 2\right) \leq T \leq\left(T_{m}+\Delta T / 2\right) \\
1 & \text { if } T>\left(T_{m}+\Delta T / 2\right)
\end{array}\right.
$$

$B(T)$ is 0 and 1 in the solid and liquid phases, respectively and linearly varies from 0 to 1 in the transition region.

Thermo-physical properties of PCM are modelled as (Biwole et al. 2013)

$$
\begin{aligned}
& \rho_{p c m}(T)=\rho_{s}+\left(\rho_{l}-\rho_{s}\right) B(T) \\
& k_{p c m}(T)=k_{s}+\left(k_{l}-k_{s}\right) B(T)
\end{aligned}
$$

The modified specific heat accounts for the latent heat of fusion for the PCM when it melts, and it is modelled as

$$
C_{p, p c m}(T)=C_{p_{s}}+\left(C_{p_{l}}-C_{p_{s}}\right) B(T)+L_{h} D(T)
$$

Modified heat capacity is defined as the common heat capacity of the PCM. $D(T)$ is used to create modified heat capacity, and its primary role is to distribute latent heat in the transition region. $D(T)$ can be expressed as (Biwole et al. 2013)

$$
D(T)=e^{\frac{-\left(T-T_{m}\right)^{2}}{(\Delta T / 4)^{2}}} / \sqrt{\pi(\Delta T / 4)^{2}}
$$


This function $D$ has a value of 0 at every region except over the interval $\left(T_{m}-\Delta T / 2\right)$ and $\left(T_{m}+\Delta T / 2\right)$, and its integral over the range of transition temperature is equal to 1 so as to satisfy the energy balance in the transition region. The additional volumetric forces, when the flow is laminar are (Biwole et al. 2013)

$$
\begin{aligned}
F_{x} & =-A(T) \cdot \vec{u} \\
F_{y} & =-A(T) \cdot \vec{v}
\end{aligned}
$$

163

\section{The thermal conductivity of the NEPCM}

$$
\begin{aligned}
& k_{n e p c m}=\frac{k_{n p}+2 k_{p c m}-2\left(k_{p c m}-k_{n p}\right) \varphi_{n p}}{k_{n p}+2 k_{p c m}+2\left(k_{p c m}-k_{n p}\right) \varphi_{n p}} k_{p c m}+B(T) b \gamma \varphi_{n p} \rho_{p c m} C_{p, p c m} \sqrt{\frac{\kappa T}{\rho_{n p} d_{n p}}} f\left(T, \varphi_{n p}\right) \\
& \text { where } \gamma=9.881\left(100 \phi_{n p}\right)^{-0.9446} \\
& f\left(T, \varphi_{n p}\right)=\left(28.217 \times 10^{-3} \varphi_{n p}+3.917 \times 10^{-3}\right) \frac{T}{T_{r e f, n p}}+\left(-30.669 \times 10^{-3} \varphi_{n p}-3.91123 \times\right. \\
& \left.10^{-3}\right)
\end{aligned}
$$

where $\varphi$ is the volume fraction of nanoparticles, $b, \kappa$ and $d_{n p}$ are constants for Brownian motion, Boltzmann constant and diameter of the nanoparticle, respectively. $T_{r e f, n p}$ is the reference temperature.

The boundary conditions at the top and bottom of the PV-NEPCM system can be expressed, respectively as

$$
\begin{gathered}
k_{g} \frac{\partial T_{g}}{\partial y}=\alpha_{g} I_{T}-h_{t}\left(T_{g}-T_{a}\right) \\
k_{a l} \frac{\partial T_{a l}}{\partial y}=h_{b}\left(T_{a l}-T_{a}\right)
\end{gathered}
$$
where $\alpha_{g}$ is the absorptivity of the glass cover. $T_{g}, T_{a l}$ and $T_{a}$ are the temperatures of glass cover, aluminium backplate and atmospherere, respectively. $h_{t}$ and $h_{b}$ are top and bottom heat transfer coefficients, respectively.

\footnotetext{
The boundary condition for sidewalls
} 


$$
\left(\frac{\partial T}{\partial x}\right)=0
$$

177 The boundary condition at the interfaces with reference to different layers is

$$
k_{m}\left(\frac{\partial T_{m}}{\partial y}\right)=k_{n}\left(\frac{\partial T_{n}}{\partial y}\right)
$$

178 where $m$ and $n$ represents two different layered materials on either sides of an interface in the system.

179 Initial condition of the system is

$$
u=0, v=0 \text { at } t=0
$$$$
T=T_{a} \text { at } t=0
$$

3. Numerical procedure, grid independence study and validation of the model

Polycrystalline PV-module is considered in the PV-NEPCM system of the present work. The properties and dimensions of each layer of PV module and aluminium plates are given in Table 1. The commercially available PCM RT25HC from Rubitherm GmbH enhanced with $\mathrm{CuO}$ nanoparticles is attached to the bottom of the PV panel with the help of aluminium plates. Thermo-physical properties of the RT25HC PCM and CuO are shown in Table 2. The volumetric concentration of nanoparticles considered in the NEPCM is $4 \%$. For PV-PCM $(\varphi=$ $0 \%)$ and PV-NEPCM $(\varphi=4 \%)$ systems, the inclination angle is changed from $0^{\circ}$ to $45^{\circ}$ in the steps of $15^{\circ}$.

Table 1 Properties and dimensions of different layered materials of PV panel and Aluminium plates

\begin{tabular}{ccccc}
\hline Material & $\begin{array}{c}\text { Density } \\
\left(\mathrm{kg} / \mathrm{m}^{3}\right)\end{array}$ & $\begin{array}{c}\text { Specific heat } \\
(\mathrm{J} / \mathrm{kg} \mathrm{K})\end{array}$ & $\begin{array}{c}\text { Thermal } \\
\text { Conductivity } \\
(\mathrm{W} / \mathrm{m} \mathrm{K})\end{array}$ & $\begin{array}{c}\text { Thickness } \\
(\mathrm{mm})\end{array}$ \\
\hline Glass & 3000 & 500 & 1.8 & 3 \\
EVA & 960 & 2090 & 0.35 & 0.5 \\
Silicon & 2330 & 677 & 0.2 & 0.3 \\
Tedler & 1200 & 1250 & 211 & 0.1 \\
Aluminium & 2675 & 903 & 2 \\
\hline
\end{tabular}

191

\begin{tabular}{|c|c|c|c|}
\hline Properties & \multicolumn{2}{|c|}{ RT25HC } & $\mathrm{CuO}$ \\
\hline \multirow[t]{2}{*}{ Density $\left(\mathrm{kg} / \mathrm{m}^{3}\right)$} & Solid & 785 & 6510 \\
\hline & Liquid & 749 & \\
\hline \multirow[t]{2}{*}{ Specific heat capacity (J/kg K) } & Solid & 1800 & 540 \\
\hline & Liquid & 2400 & \\
\hline Melting temperature $\left({ }^{\circ} \mathrm{C}\right)$ & \multicolumn{2}{|c|}{26.6} & - \\
\hline \multirow[t]{2}{*}{ Thermal conductivity (W/m K) } & Solid & 0.19 & 18 \\
\hline & Liquid & 0.18 & \\
\hline Latent heat of fusion $(\mathrm{kJ} / \mathrm{kg})$ & \multicolumn{2}{|c|}{232} & - \\
\hline
\end{tabular}

Table 2 Properties of PCM (RT25HC) (Biwole et al. 2018) and CuO (Aric1 et al. 2020) 


\begin{tabular}{ccc}
\hline Kinematic viscosity (Pa. $\mathrm{s})$ & $17.98 \times 10^{-4}$ & - \\
Thermal expansion coefficient $\left(\mathrm{K}^{-1}\right)$ & 0.001 & $0.85 \times 10^{-5}$ \\
\hline
\end{tabular}

202 For the grid dependency study, the average PV temperature (in PV-NEPCM system for $45^{\circ}$ ) with time for different

203

204

205

206

207

208

209

210

211 mesh element size combinations (maximum size, minimum size) are shown in Fig. 2. The findings suggest that the decrease in minimum size beyond $4.76 \times 0.0161 \mathrm{~mm}$ does not change the outcome, and the same is selected as the optimum for the entire study. The final complete mesh consists of 76262 domain elements and 6912 boundary elements. The time-stepping method is selected as Backward Euler. The maximum and minimum order of backward differentiation is 5 and 1 , respectively. The initial time step is fixed at $0.01 \mathrm{sec}$, and the maximum time step constraint is $2 \mathrm{sec}$. Absolute tolerance is given as $0.001 \mathrm{sec}$. A tolerance factor of 0.5 is used under a fully coupled option with a damping factor of 0.75 .

Table 3 Values of parameters used for modelling

\begin{tabular}{cc}
\hline Parameter & Value \\
\hline PCM depth $(\mathrm{mm})$ & 20 \\
$T_{i}\left({ }^{\circ} \mathrm{C}\right)$ & 20 \\
$h_{i}\left(\mathrm{~W} / \mathrm{m}^{2} \cdot \mathrm{K}\right)$ & 10 \\
$h_{o}\left(\mathrm{~W} / \mathrm{m}^{2} \cdot \mathrm{K}\right)$ & 5 \\
$T_{a}\left({ }^{\circ} \mathrm{C}\right)$ & 20 \\
$G_{T}\left(\mathrm{~W} / \mathrm{m}^{2}\right)$ & 1000 \\
$(\tau \alpha)_{e f f}$ & 0.9 \\
$\beta_{c}$ & 0.005 \\
\hline
\end{tabular}

The numerical findings are compared with the experimental results of Huang et al. (2011) for the variation of the average temperature on the system's front surface with time in Fig. 3(i) for the PV-PCM validation. The present simulated results are found to be in good agreement with the experimental values. The phase change materialnanoparticle model is validated by using the results of Arıc1 et al. (2020) by tracing the liquid fraction of a nanoenhanced square PCM cavity of size $25.4 \mathrm{~mm}$ in Fig. 3(ii). The comparisons show a reasonably good agreement between the current findings and the experimental results of Dhaidan et al. (2013) available in the literature.

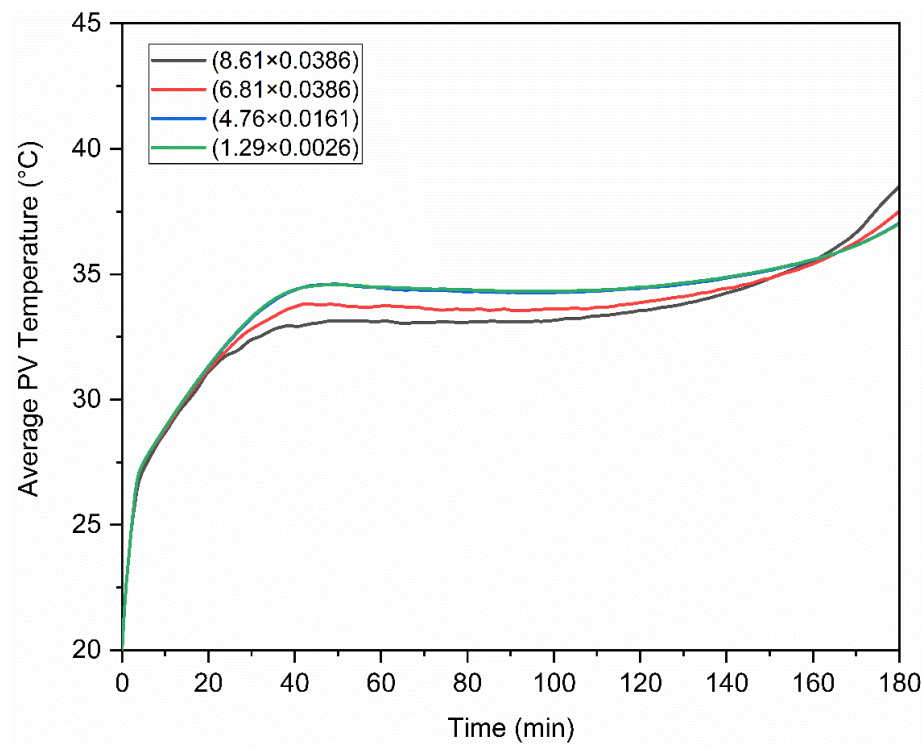

Fig. 2 Grid independence study 

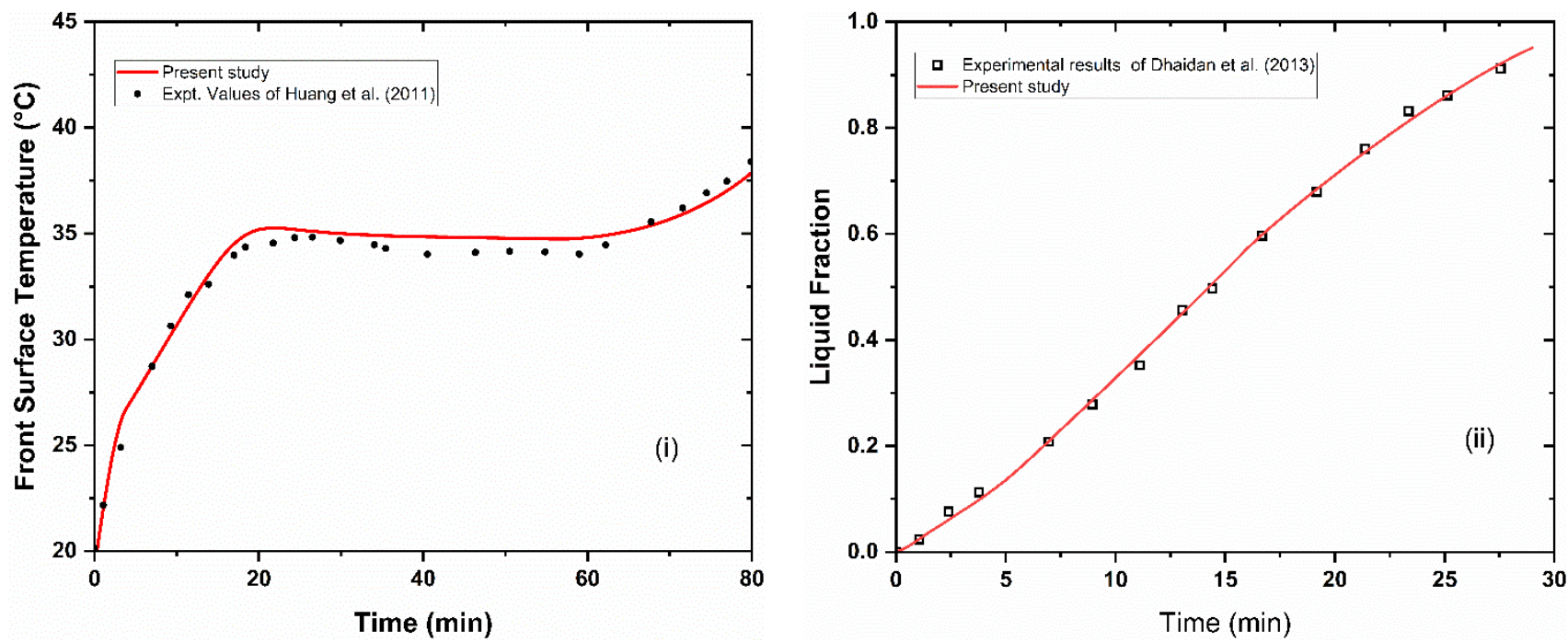

Fig. 3 (i) Comparison of (i) predicted average front surface temperature with the measured findings of Huang et al. (2011), (ii) predicted liquid fraction of NEPCM with experimental results of Dhaidan et al. (2013)

\section{Results and Discussion}

Numerical simulations are carried out to compare the thermal performance of PV-PCM $(\varphi=0 \%)$ and PV$\operatorname{NEPCM}(\varphi=4 \%)$ systems for different tilt angles from $0^{\circ}$ to $45^{\circ}$ in steps of $15^{\circ}$. The angle is varied to study the effect of natural convection inside NEPCM and the consequent performance of the PV module. The results are obtained in terms of the transient temperature profile of the PV module, the liquid fraction of NEPCM and thermal energy storage in NEPCM, which provide a better vision of the heat transfer process in the systems.

The transient variations of the mean temperature of the PV-NEPCM system for both cases $(\varphi=0 \%$ and $\varphi=$ 4\%) at different inclination angles are shown in Fig. 4. The mean temperature of the panel is highest for $\theta=0^{\circ}$, and the PV temperature decreases with the increase in tilt angle. This is because, for a horizontal system $\left(\theta=0^{\circ}\right)$, conduction is the mechanism of heat transfer existing in the system. Convection heat transfer is not exiting in the system due to the thermally stable state of the PCM, which will not give rise to the buoyancy force and the consequent natural convection currents. The low thermal conductivity of the PCM leads to a lower heat transfer rate within the pure PCM $(\varphi=0 \%)$. For NEPCM $(\varphi=4 \%)$, the thermal conductivity increases with the presence of the nanoparticles, which results in an increased conduction heat transfer rate compared to pure PCM ( $\varphi=0 \%)$ for the horizontal system. Hence, the mean PV temperature of PV-NEPCM is less compared to that of the PV-PCM for horizontal systems. As the tilt angle increases, the temperature difference existing in the melted PCM between the location at the bottom of the PV module and the location far away from the bottom gives rise to establishing the gravitational field and consequent existence of buoyant force. This buoyant force is dominant over the inertial and viscous forces, which establishes the natural convection current and the existence of natural convection heat transfer mechanism within the melted PCM. This leads to an obvious enhancement of the rate of heat extraction by PCM, resulting in lower PV temperature. The strength of the natural convection current and, thereby, heat transfer rate increases with the increase in inclination. PV temperature $\left(1.10^{\circ} \mathrm{C}\right)$ is obtained for $\theta=0^{\circ}$, the horizontal system as shown in Fig. 5. For systems with inclinations greater than zero, the combined existence of natural convection and higher thermal conductivity of 
NEPCM seems to regulate the temperature of the module better compared to horizontal systems. However, higher viscosity results with the addition of nanoparticles in the PCM in the liquid phase results in higher fluid friction and consequent reduction in the strength of natural convection current in the NEPCM systems and finally, the dominance of the reduction in mean PV temperature reduces with the inclination considerably. The temperature reduction while using NEPCM for $\theta=45^{\circ}$ is only $0.454^{\circ} \mathrm{C}$. Moreover, the addition of nanoparticles lowers the latent heat of NEPCM, which affects the thermal regulation period. After the complete melting of the NEPCM, the average PV temperature increases again at a rate higher than in simple PCM. The higher the tilt angle, the lower the thermal regulation period, which can be seen in Fig. 4.
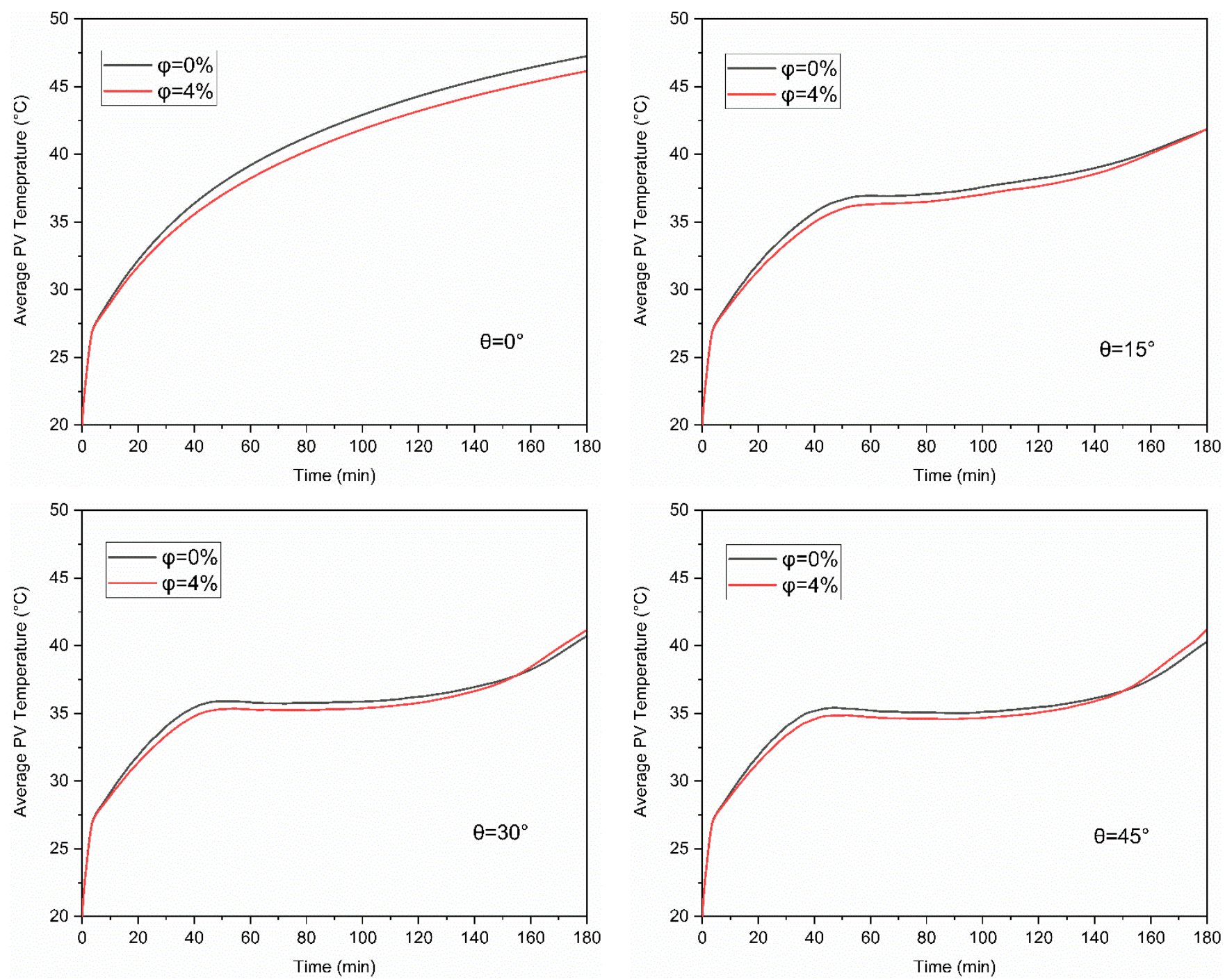

Fig. 4 Comparison of the transient mean PV temperature with different inclinations at vol.\% 0 and 4 of 


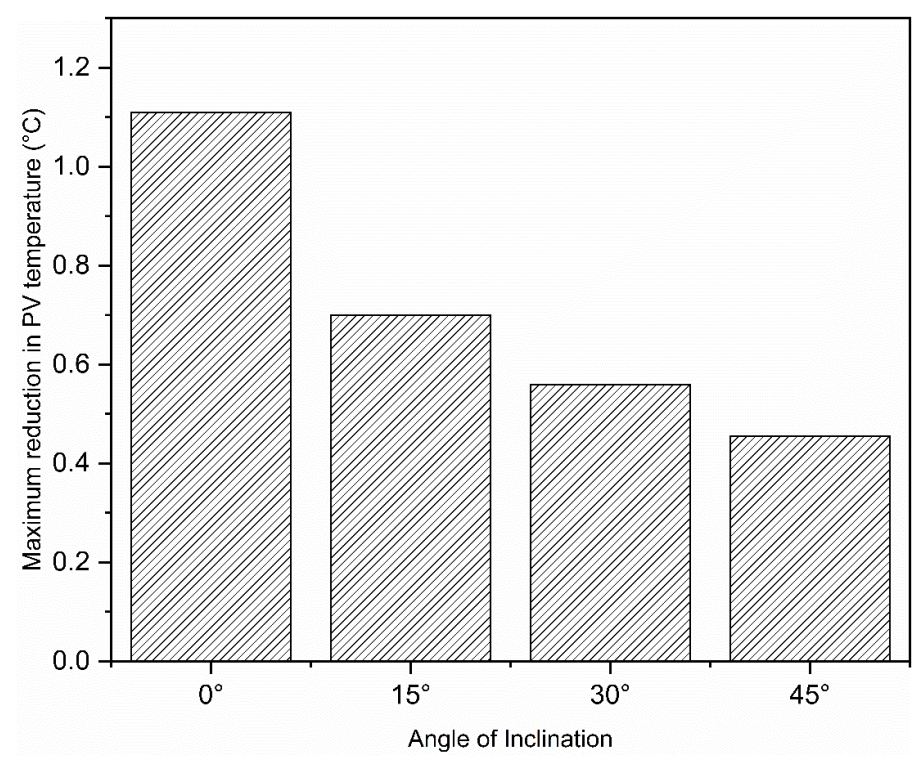

The transient variations of liquid fraction for PV-PCM and PV-NEPCM systems at various inclinations are shown in Fig. 6. The melting rate is slower for $\theta=0^{\circ}$ in both systems. As inclination increases, the melting rate also increases because of the enhanced energy transfer rate owing to increased buoyant force and thereby convection current in both systems. For the PV-NEPCM system, the melting occurs faster for all tilt angles compared to the PV-PCM system. The effect of adding nanoparticles is more pronounced for the horizontal system when $\theta=0^{\circ}$. For horizontal systems, conduction is the mechanism of heat transfer existing in the PCM, and by adding nanoparticles, the thermal conductivity of NEPCM increases and thereby increased the rate of heat transfer and consequent melting rate. Although there is an enhancement in thermal conductivity for inclined systems with the inclusion of nanoparticles, the natural convection current inside PCM is reduced slightly by increased viscosity due to nanoparticles' presence. This causes the effect of the inclusion of nanoparticles on the melting rate of NEPCM in PV-NEPCM systems less at higher inclinations. In addition to this, an increase in nanoparticles reduces the latent heat of the NEPCM and consequent reduction in the thermal regulation period at higher inclinations which can be seen with lower slopes of liquid fraction trends. From Fig. 7, it is clear that the enhancement in the liquid fraction when adding $\mathrm{CuO}$ nanoparticles is highest (7.6\%) for the horizontal system, whereas it is only $3.1 \%$ for $\theta=45^{\circ}$ when $t=150 \mathrm{~min}$.

Fig. 8 shows the temporal evolution of thermal energy stored for PCM and NEPCM systems at various tilt angles. The energy stored is strongly related to the liquid fraction; as the tilt angle increases, the energy stored is more. The amount of energy stored is lowest when $\theta=0^{\circ}$ for both systems as the melting is carried out mainly by the presence of conduction heat transfer. With the NEPCM system, the energy stored is increased considerably for $\theta=0^{\circ}$ due to enhanced conduction heat transfer compared to the other system. Variation of energy stored in NEPCM at $t=150 \mathrm{~min}$ is shown in Fig. 9 for both the systems at various inclination angles. The thermal energy stored in simple PCM is $400.5 \mathrm{~kJ}$ against $415.78 \mathrm{~kJ}$ for NEPCM at $\theta=0^{\circ}$. There is only a slight increase in the amount of energy stored for higher tilt angles with the loading of nanoparticles in the system, as natural convection is affected by high viscosity and lower latent heat in NEPCM. The improvement in thermal energy stored is only 

system.
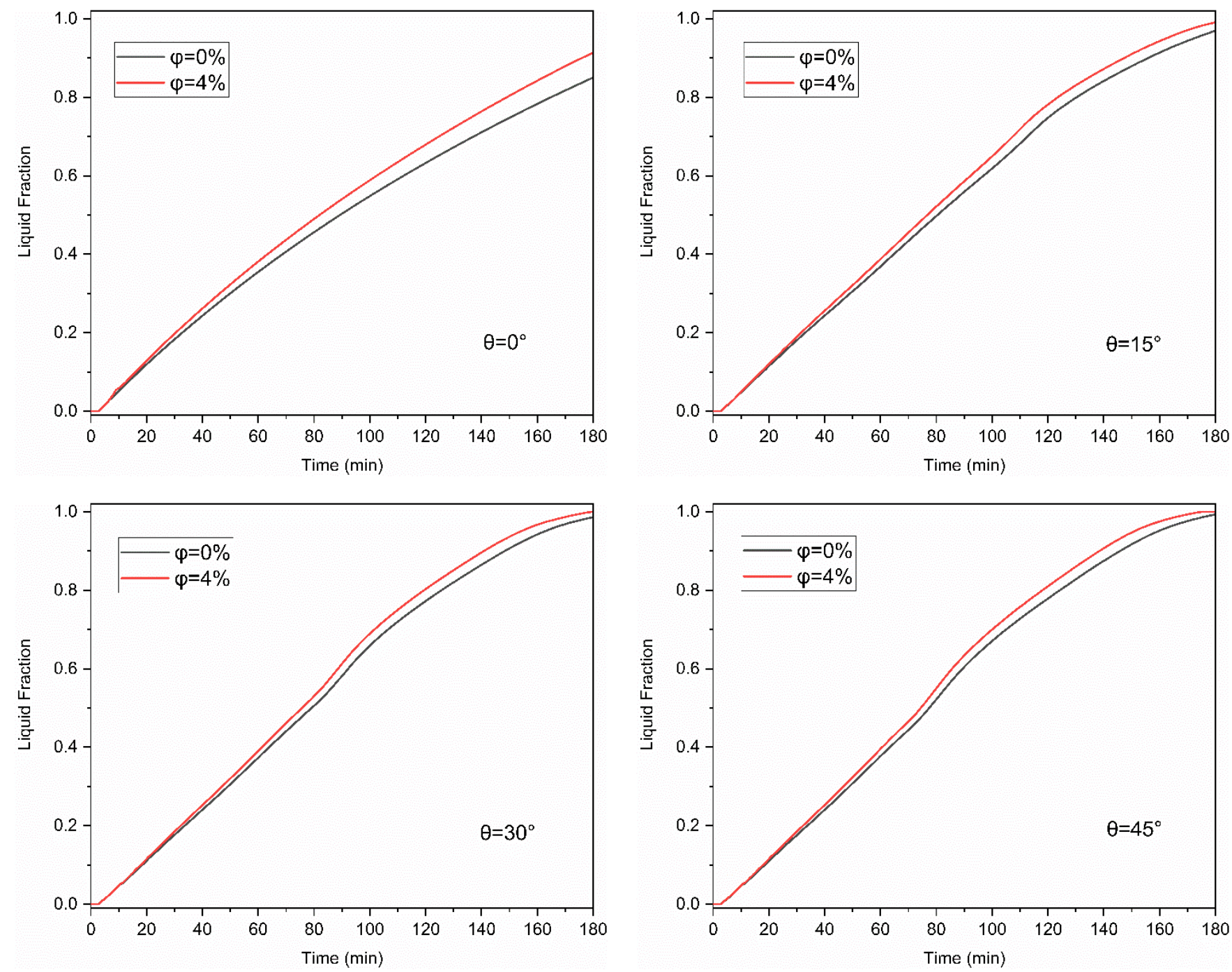

Fig. 6 Variation of liquid fraction with time for PCM with $\varphi=0 \%$ and $\varphi=4 \%$ at different tilt angles

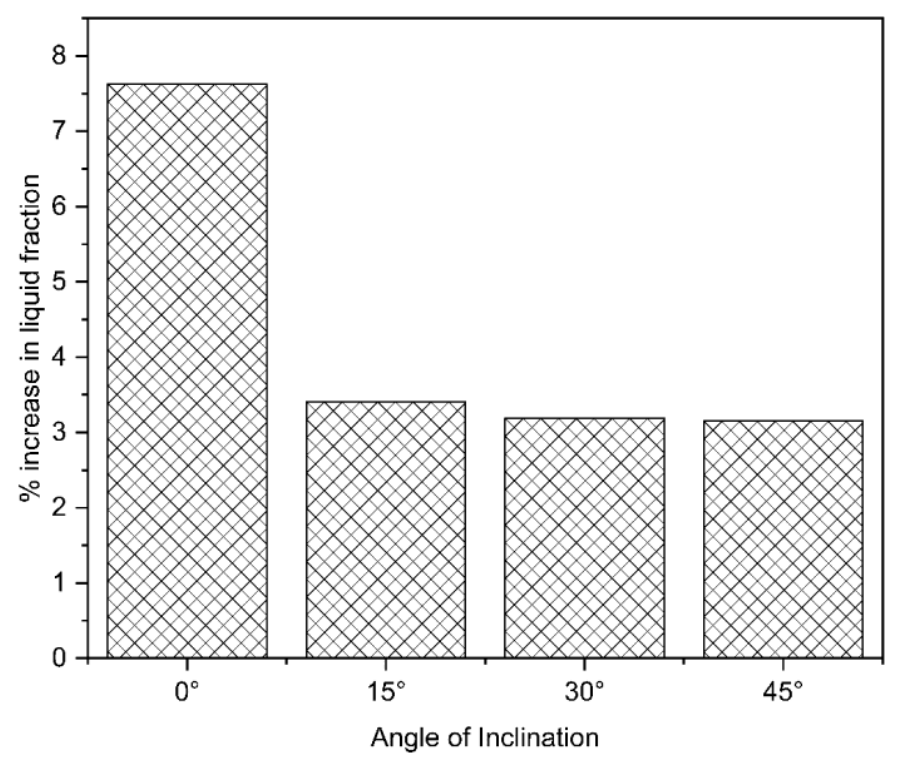

Fig. 7 Percentage increase in the liquid fraction of NEPCM at $t=150 \mathrm{~min}$ for all inclinations 

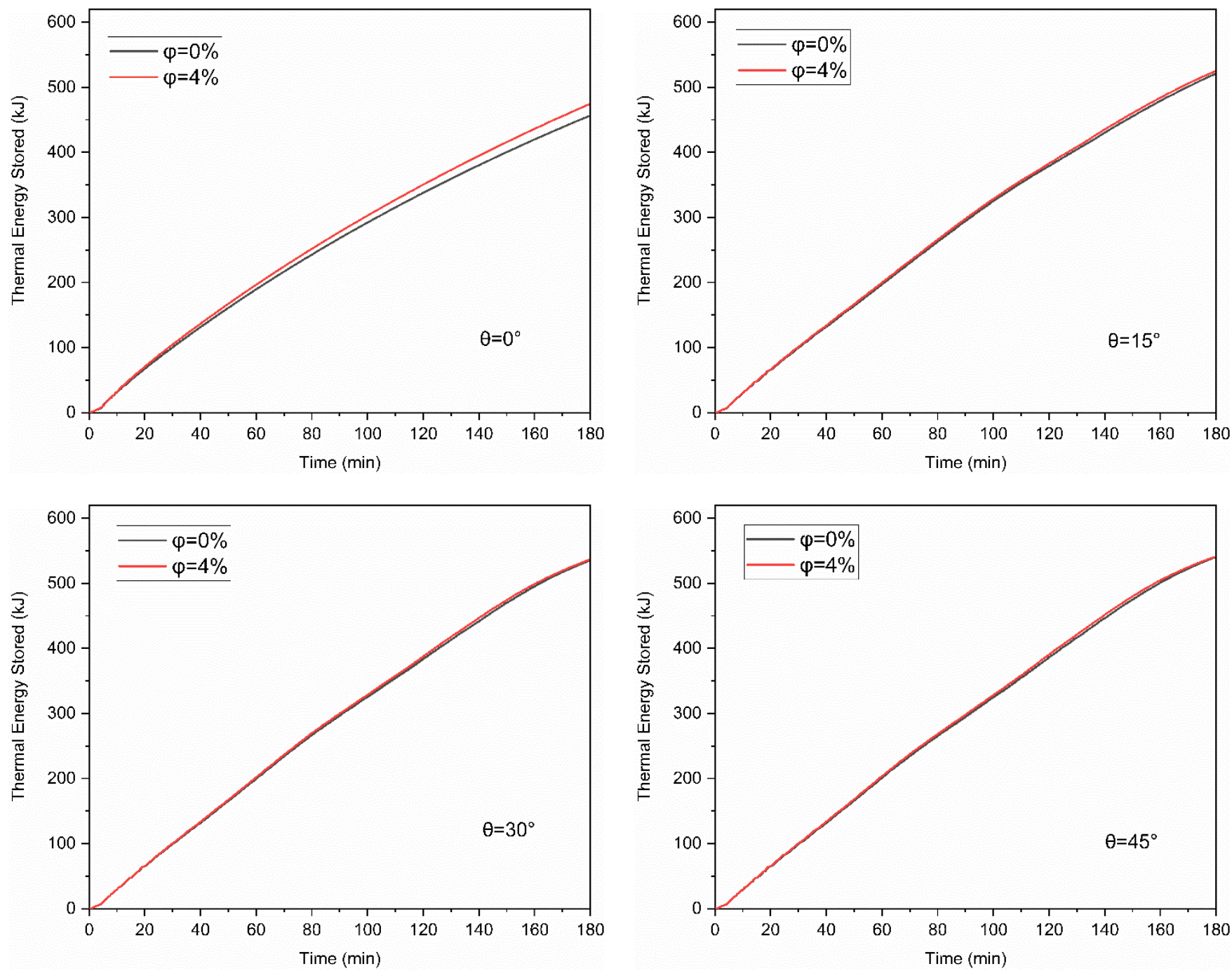

Fig. 8 Variation of thermal energy stored in PCM with time for $\varphi=0 \%$ and $\varphi=4 \%$ at different tilt angles

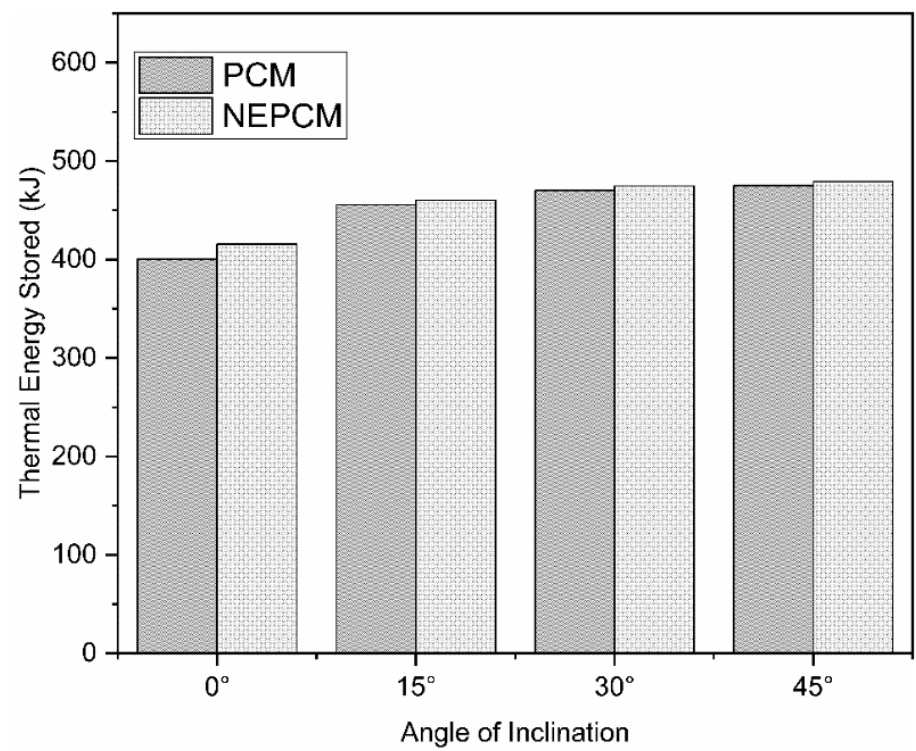



systems are shown in Fig. 10. As the reduction in PV temperature positively affects its efficiency, the PV efficiency for the PV-NEPCM system is higher than that of the PV-PCM system at all inclinations. As the temperature reduction is highest in the case of horizontal PV-NEPCM systems with $\theta=0^{\circ}$, the maximum enhancement in the efficiency of PV module (1.6\%) is also highest for PV-NEPCM system with $\theta=0^{\circ}$ (see Fig. 11). As convection heat transfer becomes prominent for higher inclinations, the effect of nanoparticles become lesser due to an increase in viscosity and fluid friction, as explained earlier, which leads to less increase in efficiency with time in PV-NEPCM systems over PV-PCM systems. The effect of nanoparticles on the increase in efficiency of the module continuously increases with time for horizontal systems since the phase change of PCM and NEPCM were not completed in the respective systems for the duration considered in the simulation. Contrary to this, the thermal regulation period reduces due to reduction in latent heat for $\operatorname{NEPCM}(\varphi=4 \%)$, which causes the reduction in efficiency of the module compared to $\operatorname{PCM}(\varphi=0 \%)$ after the completion of the phase change process in PV-NEPCM systems. The improvement in PV efficiency is observed up to the melting period of NEPCM for all the inclinations. Maximum percentage enhancement of efficiency of the module decreases with an increase in inclination as the value is only $0.86 \%$ for $\theta=45^{\circ}$, as shown in Fig. 11 .
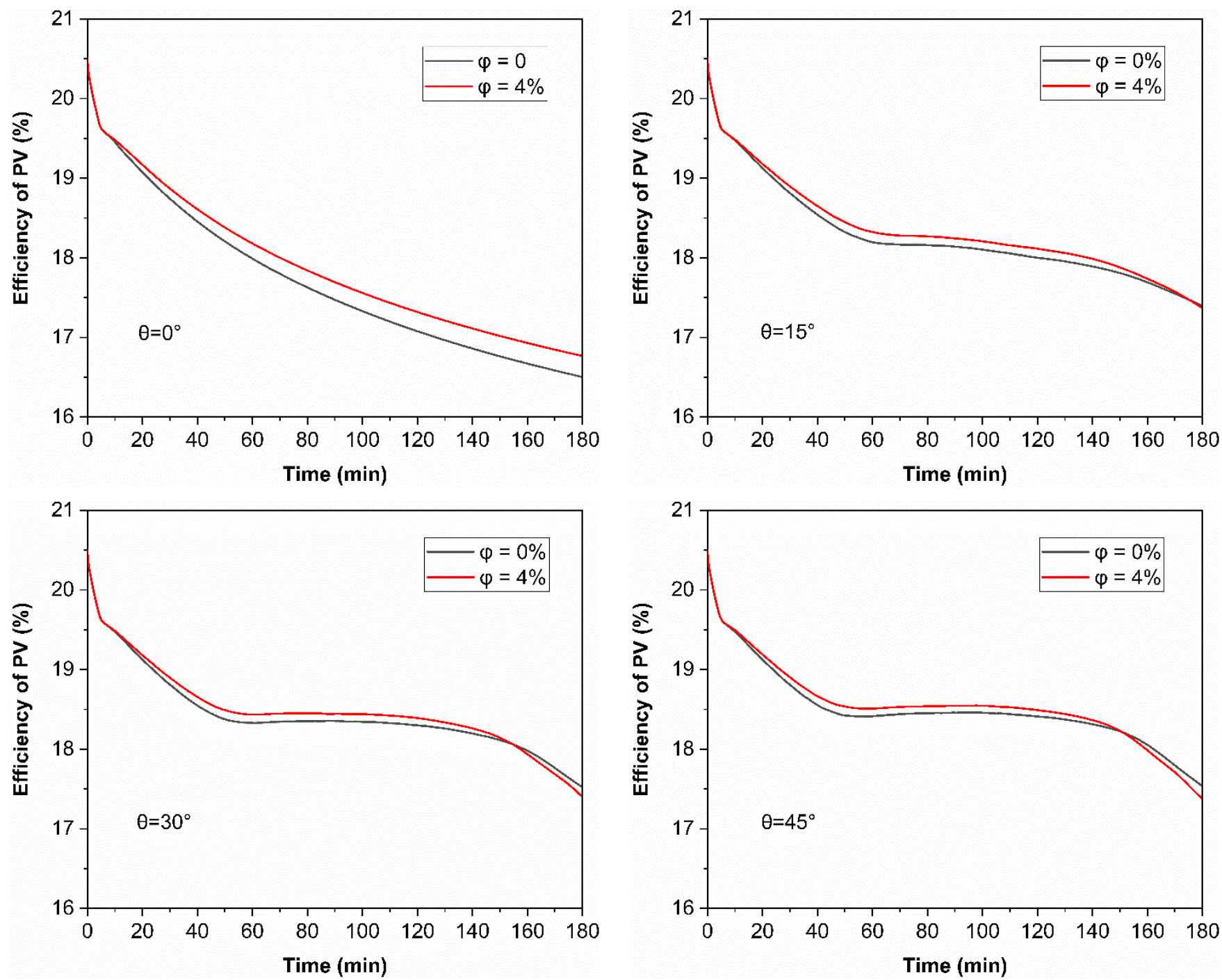
Fig. 10 Comparison of the efficiency of PV with time at different inclinations with vol.\% 0 and 4 of nanoparticles

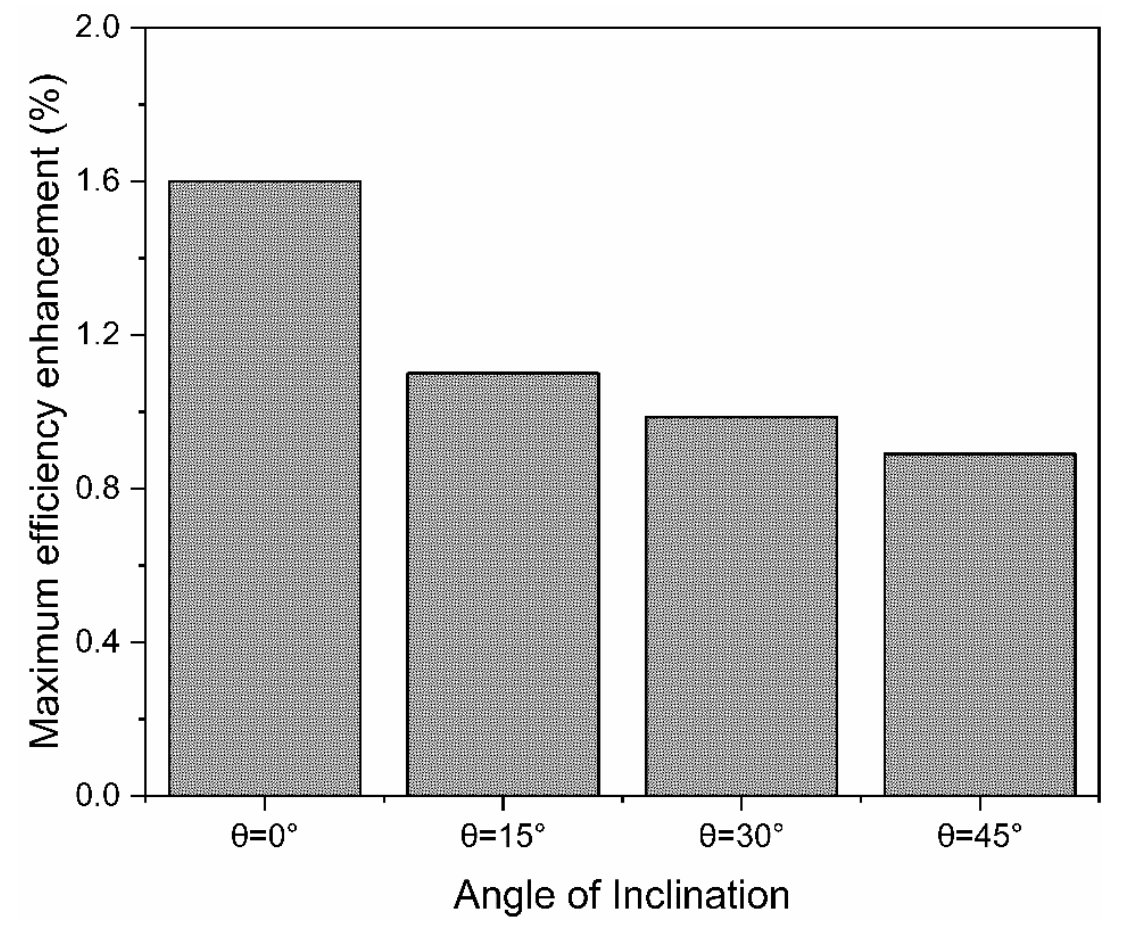

Fig. 11 Maximum efficiency enhancement of PV for PV-NEPCM system when compared to PV-PCM system at different inclinations

\section{Conclusions}

In the present work, numerical investigations of a PV integrated with pure PCM (PV-PCM system) and nanoenhanced PCM (PV-NEPCM) system with a volumetric concentration of 4\% are carried out for 180 min duration. The outcomes of the study can be summarised as follows:

(i) At an early stage, melting is dominated by conduction. Convection heat transfer mechanism is an important factor, especially for higher tilt angles at later times, thereby leading to higher liquid fraction rate and energy stored in PCM.

(ii) PV integrated with nano-enhanced PCM is more effective for lower tilt angles. Maximum average temperature reduction of $\mathrm{PV}\left(1.11^{\circ} \mathrm{C}\right)$ is obtained when $\theta=0^{\circ}$.

(iii) The percentage increase in the liquid fraction for $\operatorname{NEPCM}(\varphi=4 \%)$ compared with $\operatorname{PCM}(\varphi=$ $0 \%$ ) is $7.6 \%$ for $\theta=0^{\circ}$ as compared to $3.15 \%$ for $\theta=45^{\circ}$ at $t=150 \mathrm{~min}$.

(iv) For NEPCM, the percentage increase in the amount of energy stored when compared with PCM is $3.82 \%$ for horizontal system against $0.91 \%$ for the system with an inclination of $45^{\circ}$ at $t=150 \min$.

(v) Improvement in PV efficiency is obtained for the PV-NEPCM systems. The highest Maximum enhancement of $1.6 \%$ is obtained for $\theta=0^{\circ}$ inclination.

Nomenclature

$A \quad$ upper surface of the PV panel $\left(\mathrm{m}^{2}\right)$

$C_{p} \quad$ heat capacity (J/kg. K) 


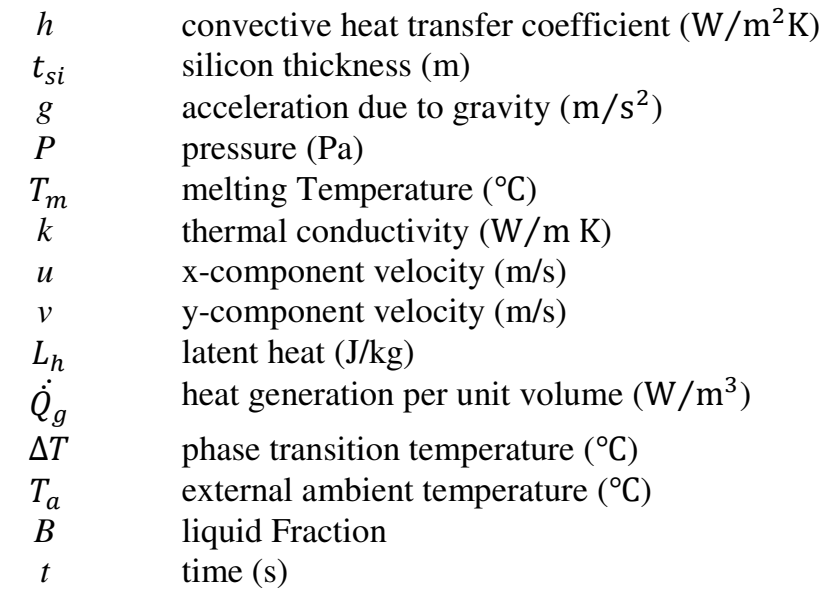

Greek Symbols

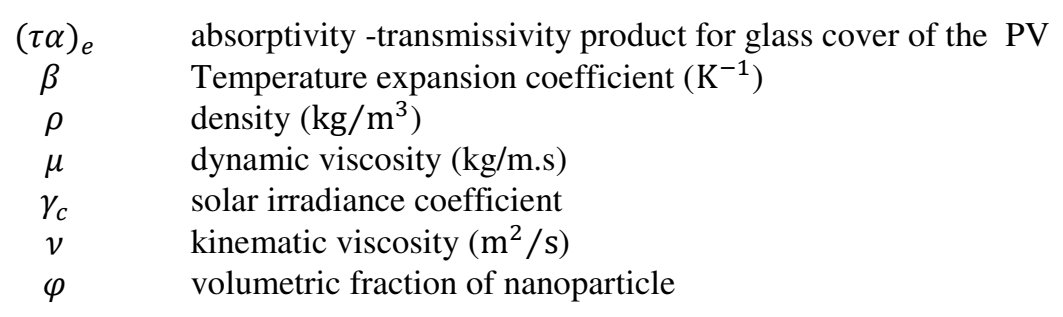

335 Subscripts

$\begin{array}{cl}a & \text { external ambient } \\ g & \text { Glass } \\ P & \text { PCM } \\ x & \text { along x } \\ y & \text { along y } \\ s i & \text { Silicon } \\ a l & \text { Aluminium } \\ t & \text { top } \\ b & \text { bottom }\end{array}$

336 Acronyms/Abbreviations

$\begin{array}{cl}\text { PCM } & \text { phase change material } \\ \text { NEPCM } & \text { nano-enhanced phase change material } \\ \text { EVA } & \text { ethylene-vinyl acetate } \\ \text { PV } & \text { Photovoltaic } \\ \text { PV-PCM } & \text { photovoltaic-phase change material system } \\ \text { PV-NEPCM } & \text { nano-enhanced photovoltaic-phase change material system }\end{array}$

\section{Declarations}

Acknowledgments

Not applicable

\section{Authors' contributions}

342 Unnikrishnan Karthamadathil Sasidharan has contributed to the main conceptual idea, study design and full article

343 writing. Rohinikumar Bandaru has involved in the technical discussions, checked the review connectivity and improved the write-up. 
The datasets used and/or analyzed during the current study are available from the corresponding author on reasonable request.

\section{Compliance with ethical standards}

Not appicable

\section{Ethics approval and consent to participate}

351 Not applicable.

\section{Consent for publication}

353 Not applicable.

\section{$354 \quad$ Funding}

$355 \quad$ Not applicable

\section{Competing interests}

357 The authors declare that they have no competing interests.

358

359

360

361

362

\section{References}

Arasu A valan, Sasmito AP, Mujumdar AS (2013) Numerical performance study of paraffin wax dispersed with alumina in a concentric pipe latent heat storage system. Therm Sci 17:419-430. https://doi.org/10.2298/TSCI110417004A

Arıcı M, Tütüncü E, Yıldız Ç, Li D (2020) Enhancement of PCM melting rate via internal fin and nanoparticles. Int J Heat Mass Transf 156:. https://doi.org/10.1016/j.ijheatmasstransfer.2020.119845

Atkin P, Farid MM (2015) Improving the efficiency of photovoltaic cells using PCM infused graphite and aluminium fins. Sol Energy 114:217-228. https://doi.org/10.1016/j.solener.2015.01.037

Biwole PH, Eclache P, Kuznik F (2013) Phase-change materials to improve solar panel's performance. Energy Build 62:59-67. https://doi.org/10.1016/j.enbuild.2013.02.059

Biwole PH, Groulx D, Souayfane F, Chiu T (2018) Influence of fin size and distribution on solid-liquid phase change in a rectangular enclosure. Int J Therm Sci 124:433-446. https://doi.org/10.1016/j.ijthermalsci.2017.10.038

Brano V Lo, Ciulla G, Piacentino A, Cardona F (2013) On the Efficacy of PCM to Shave Peak Temperature of Crystalline Photovoltaic Panels: An FDM Model and Field Validation. Energies 6:6188-6210. https://doi.org/10.3390/en6126188

Brent AD, Voller VR, Reid KJ (1988) Enthalpy-porosity technique for modeling convection-diffusion phase change: Application to the melting of a pure metal. Numer Heat Transf 13:297-318. https://doi.org/10.1080/10407788808913615

C. VVR\& P (1978) A Fixed grid numerical modelling methodology for convection diffusion mushy region phase change problems. Int Jounal Heat Mass Transf 30:1709-1719

Ceylan İ, Gürel AE, Ergün A (2017) The mathematical modeling of concentrated photovoltaic module temperature. Int J Hydrogen Energy 42:19641-19653. https://doi.org/10.1016/j.ijhydene.2017.06.004

David Tan AKS (2011) Handbook for Solar Photovoltaic Systems. Energy Mark Authority, Singapore Publ 4-9

Dhaidan NS, Khodadadi JM, Al-Hattab TA, Al-Mashat SM (2013) Experimental and numerical investigation of melting of phase change material/nanoparticle suspensions in a square container subjected to a constant heat flux. Int J Heat Mass Transf 66:672-683. https://doi.org/10.1016/j.ijheatmasstransfer.2013.06.057 
E. Radziemska (2002) The effect of temperature on the power drop in crystalline silicon solar cells. In: Renew Energy 2003;28:1-12. IEEE, pp 3574-3578

Emam M, Ookawara S, Ahmed M, et al (2017) Performance study and analysis of an inclined concentrated photovoltaic-phase change material system. Sol Energy 150:229-245. https://doi.org/10.1016/j.solener.2017.04.050

Evans DL, Florschuetz LW (1977) Cost studies on terrestrial photovoltaic power systems with sunlight concentration. Sol Energy 19:255-262. https://doi.org/10.1016/0038-092X(77)90068-8

Gkouskos Z, Tsoutsos T (2012) Integrating phase change material to photovoltaics in a mediterranean region. Photovolt Sol Energy ...

Hachem F, Abdulhay B, Ramadan M, et al (2017) Improving the performance of photovoltaic cells using pure and combined phase change materials - Experiments and transient energy balance. Renew Energy 107:567-575. https://doi.org/10.1016/j.renene.2017.02.032

Hasan A, McCormack SJ, Huang MJ, Norton B (2010) Evaluation of phase change materials for thermal regulation enhancement of building integrated photovoltaics. Sol Energy 84:1601-1612. https://doi.org/10.1016/j.solener.2010.06.010

Hegedus S (2003) Photovoltaic Science

Huang MJ, Eames PC, Norton B (2006) Comparison of a small-scale 3D PCM thermal control model with a validated 2D PCM thermal control model. Sol Energy Mater Sol Cells 90:1961-1972. https://doi.org/10.1016/j.solmat.2006.02.001

Huang MJ, Eames PC, Norton B, Hewitt NJ (2011) Natural convection in an internally finned phase change material heat sink for the thermal management of photovoltaics. Sol Energy Mater Sol Cells 95:15981603. https://doi.org/10.1016/j.solmat.2011.01.008

Kant K, Shukla A, Sharma A, Biwole PH (2016) Heat transfer studies of photovoltaic panel coupled with phase change material. Sol Energy 140:151-161. https://doi.org/10.1016/j.solener.2016.11.006

Khanna S, Reddy KS, Mallick TK (2017) Performance analysis of tilted photovoltaic system integrated with phase change material under varying operating conditions. Energy 133:887-899. https://doi.org/10.1016/j.energy.2017.05.150

Klemm T, Hassabou A, Abdallah A, Andersen O (2017) Thermal energy storage with phase change materials to increase the efficiency of solar photovoltaic modules. Energy Procedia 135:193-202. https://doi.org/10.1016/j.egypro.2017.09.502

Luo Z, Huang Z, Xie N, et al (2017) Numerical and experimental study on temperature control of solar panels with form-stable paraffin/expanded graphite composite PCM. Energy Convers Manag 149:416-423. https://doi.org/10.1016/j.enconman.2017.07.046

Mahamudul H, Rahman MM, Metselaar HSC, et al (2016) Temperature Regulation of Photovoltaic Module Using Phase Change Material: A Numerical Analysis and Experimental Investigation. Int J Photoenergy 2016:1-8. https://doi.org/10.1155/2016/5917028

Maiti S, Banerjee S, Vyas K, et al (2011) Self regulation of photovoltaic module temperature in V-trough using a metal-wax composite phase change matrix. Sol Energy 85:1805-1816. https://doi.org/10.1016/j.solener.2011.04.021

Mat S, Al-Abidi AA, Sopian K, et al (2013) Enhance heat transfer for PCM melting in triplex tube with internalexternal fin[1] S. Mat, A.A. Al-Abidi, K. Sopian, M.Y. Sulaiman, A.T. Mohammad, Enhance heat transfer for PCM melting in triplex tube with internal-external fins, Energy Convers. Manag. 7. Energy Convers Manag 74:223-236. https://doi.org/10.1016/j.enconman.2013.05.003 
Nouira M, Sammouda H (2018) Numerical study of an inclined photovoltaic system coupled with phase change material under various operating conditions. Appl Therm Eng 141:958-975. https://doi.org/10.1016/j.applthermaleng.2018.06.039

Otth DH, Ross RG (1983) Assessing Photovoltaic Module Degradation and Lifetime From Long Term Environmental Tests. Proceedings, Annu Tech Meet - Inst Environ Sci 121-126

Park J, Kim T, Leigh SB (2014) Application of a phase-change material to improve the electrical performance of vertical-building-added photovoltaics considering the annual weather conditions. Sol Energy 105:561574. https://doi.org/10.1016/j.solener.2014.04.020

Radziemska E, Klugmann E (2002) Thermally affected parameters of the current-voltage characteristics of silicon photocell. Energy Convers Manag 43:1889-1900. https://doi.org/10.1016/S0196-8904(01)00132-7

Sinks MH, Singh P, Khanna S, et al (2020) Solar Photovoltaic Panels with Finned Phase Change. Energies 17

439

Skoplaki E, Palyvos JA (2009) On the temperature dependence of photovoltaic module electrical performance: A review of efficiency/power correlations. Sol Energy 83:614-624. https://doi.org/10.1016/j.solener.2008.10.008

Sourav, Newar S, Sharma V, et al (2019) Electrical enhancement period of solar photovoltaic using phase change material. J Clean Prod 221:878-884. https://doi.org/10.1016/j.jclepro.2019.02.169

Vajjha RS, Das DK (2009) Experimental determination of thermal conductivity of three nanofluids and development of new correlations. Int J Heat Mass Transf 52:4675-4682. https://doi.org/10.1016/j.ijheatmasstransfer.2009.06.027

Wysocki JJ, Rappaport P (1960) Effect of Temperature on Photovoltaic Solar Energy Conversion. J Appl Phys 31:571-578. https://doi.org/10.1063/1.1735630

Zarma I, Ahmed M, Ookawara S (2019) Enhancing the performance of concentrator photovoltaic systems using Nanoparticle-phase change material heat sinks. Energy Convers Manag 179:229-242. https://doi.org/10.1016/j.enconman.2018.10.055 